\title{
Uranium isotope constraints on the dynamics of global carbon cycle perturbations
}

\section{S. J. ROMANIELLO ${ }^{1 *}$}

1. University of Tennessee, Department of Earth and Planetary Sciences, Knoxville, TN, USA (sromanie@utk.edu)

The Phanerozoic carbon isotope record contains numerous examples of both large positive and negative carbon isotope excursions corresponding to global-scale perturbations in Earth's carbon cycle. Each of these events is thought to result in a cascade of biogeochemical feedbacks including changes in temperature, weathering rates, nutrient transport, primary productivity, eventually leading to possible changes in marine redox conditions. By tracking changes in ocean anoxia at the tail end of this chain of events, the uranium isotope paleoredox proxy is emerging as a potent tool for unravelling the timing, causes, and consequences of large carbon cycle perturbations through the Phanerozoic

Here I will highlight the recent application of the $\mathrm{U}$ isotope proxy to Early Triassic where a series of negative carbon isotope excursions correspond to repeated cycles of $\mathrm{CO}_{2}$ injection, warming, enhanced weathering, and expanded anoxia which contributed to the protracted recovery from the end-Permian mass extinction. I will also provide a counterexample from the Early Mississippian Tournaisian carbon isotope event (TICE), where $\mathrm{U}$ isotopes provide evidence that expanded marine anoxia drove enhanced carbon burial and ultimately initiated late Paleozoic cooling.

Finally, I will discuss efforts to address the most significant hurdles remaining in our quantitative understanding of $\mathrm{U}$ isotope systematics, including the impact of carbonate mineralogy and bottom water redox conditions on syndepositional diagenesis of $\delta^{238} \mathrm{U}$ and the role of anoxic and ferruginous conditions in controlling the isotopic mass balance of $\mathrm{U}$ in the global ocean. 